Dr Kasper Sipowicz, https:/ / orcid.org/0000-0001-7384-2899

Akademia Pedagogiki Specjalnej

im. Marii Grzegorzewskiej w Warszawie

Katedra Interdyscyplinarnych Studiów

nad Niepetnosprawnościa

Mgr Marlena Podlecka, https:// orcid.org/0000-0002-2213-374X

Instytut Psychiatrii i Neurologii w Warszawie

Klinika Nerwic, Zaburzeń Osobowości i Odżywiania

Dr hab. n. med. prof. UM Tadeusz Pietras, https://orcid.org/0000-0003-1771-3819

Instytut Psychiatrii i Neurologii w Warszawie

II Klinika Psychiatryczna

\title{
Systemowe rozumienie rodziny a schizofrenia - czy koncepcja matki schizofrenogennej wytrzymała próbę czasu?
}

\section{A systemic understanding of the family and schizophrenia \\ - has the concept of the schizophrenogenic mother stood the test of time?}

https://doi.org/10.34766/fetr.v45i1.711

\begin{abstract}
Abstrakt: W niniejszym artykule zarysowana została zmieniająca się koncepcja pojmowania schizofrenii. Dawniej w kontekście systemowej terapii rodzin, przyczyn owej choroby upatrywano w reakcji najsłabszego członka rodziny na obecność tzw. matki schizofrenogennej. Jednak zgodnie z hipotezą neurorozwojową przyjmuje się współcześnie, iż rozwój schizofrenii może być następstwem nieprawidłowego rozwoju płodu. Wiedza ta rzuca nowe światło na rozumienie etiopatologii owego zaburzenia, zdejmując także piętno z rodzin osób chorych i otwierając efektywną ścieżkę terapii systemowej rodzin osób ze schizofrenią.

Słowa kluczowe: hipoteza neurorozwojowa schizofrenii, matka schizofrenogenna, schizofrenia $\mathrm{w}$ rodzinie, terapia systemowa rodzin
\end{abstract}

Abstract: This article outlines the changing concept of understanding schizophrenia. Formerly, in the context of systemic family therapy, the cause of this illness was seen in the reaction of the weakest family member to the presence of the so-called schizophrenogenic mother. However, according to the neurodevelopmental hypothesis, it is now accepted that the development of schizophrenia is a consequence of abnormal foetal development. This knowledge sheds new light on the understanding of the etiopathology of this disorder, thus removing the stigma from the families of sick people and opening an effective path of systemic therapy for families of people with schizophrenia.

Keywords: neurodevelopmental hypothesis of schizophrenia, schizophrenogenic mother, schizophrenia and family, systemic family therapy 


\section{Wprowadzenie}

Według najnowszych poglądów schizofrenia może rozwijać się wskutek nieprawidłowego rozwoju płodu. Koncepcja ta, nazywana hipotezą neurorozwojową schizofrenii, jest dość dobrze udokumentowana empirycznie. Sformułował ją zespół badaczy zajmujących się czynnikami genetycznymi i neuropsychologicznymi schizofrenii. Wśród nich należy wymienić: Robina Murray'a (1987), Daniela Weinbergera (1987), Barbarę Lipską (2004) oraz Nancy Andreasen (2010). Podstawowym założeniem hipotezy neurorozwojowej schizofrenii jest wynikający $\mathrm{z}$ iloczynu czynników genetycznych i środowiskowych nieprawidłowy rozwój mózgowia. Tło rozwoju schizofrenii może być zatem zbliżone do niepełnosprawności intelektualnej, autyzmu i mózgowego porażenia dziecięcego (Pietras i in., 2012).

Uszkodzenie mózgowia w schizofrenii jest na tyle minimalne, że przejawia się ono psychozą dopiero po okresie dojrzewania. Jest to tzw. okres trzebieży neuronów, w przebiegu którego dochodzi do wygaszenia zbędnych połączeń w OUN. Ważnym pośrednim dowodem słuszności hipotezy neurorozwojowej jest hipoteza dopaminowa schizofrenii sformułowana przez Arvida Carlssona (za: Foley, 2019). Zakłada ona, że zwiększona aktywność szlaków dopaminergicznych (dziś już wiadomo, że szlaku mezolimbicznego) wiąże się z projekcją psychotyczną (Stahl, 2013). Neuroleptyki, czyli leki przeciwpsychotyczne, blokują przekaźnictwo dopaminergiczne, wygaszając objawy choroby.

Od dawna wiadomo, że schizofrenia zaburza znacznie funkcjonowanie systemu rodzinnego (por. np. Addington, 2005). Przed sformułowaniem hipotezy neurorozwojowej zastanawiano się, czy przypadkiem owo zaburzenie nie rozwija się na skutek nieprawidłowych relacji $\mathrm{w}$ systemie rodziny nuklearnej. Od końca XX wieku przeważa pogląd, że system jakim jest rodzina zostaje rozregulowany przez obecność schizofrenii, a także przez drobne deficyty funkcji poznawczych i emocjonalnych występujące u członków rodzin (Genderson i in., 2007).

Celem artykułu jest krótki opis współczesnej terapii rodzin pod kątem pomocy osobom ze schizofrenią oraz refleksja na temat skutków społecznych koncepcji tzw. matki schizofrenogennej.

\section{Systemowe rozumienie rodziny}

Systemowa psychoterapia rodzin rozwinęła się jako wieloletni proces ewolucyjny począwszy od psychoanalitycznego rozumienia rodziny, poprzez teorię systemów, szkołę strategiczną, szkołę strukturalną, szkołę mediolańską oraz wiele innych nurtów pokrewnych (Namysłowska, 2000). Nie jest celem tego artykułu omawianie historii terapii rodzin, gdyż 
na rynku polskim obecne są znane monografie pod redakcją Bogdana de Barbaro (1999a, 1999b), Ireny Namysłowskiej (2000) oraz Herberta i Ireny Goldenbergów (2006). Warto jednak zaprezentować współczesne stanowisko w terapii rodzin.

Systemowa teoria terapii rodzin ujmuje rodzinę nuklearną złożoną z rodziców i dzieci jako system o wyraźnie wyodrębnionych granicach, który kosztem zewnętrznej entropii informacyjnej utrzymuje własny wysoki poziom organizacji. System rodzinny złożony jest z wielu podsystemów (np. podsystem pary rodzicielskiej, pary małżeńskiej, podsystem dzieci, podsystem mężczyzn oraz kobiet), a zarazem sam jest częścią większych systemów, w szczególności systemu rodziny rozszerzonej, przez którą rozumie się $\mathrm{w}$ psychologii systemowej zbiór wszystkich powinowatych i krewnych. System rodzinny, podobnie jak każdy system regulacji stabilnej, posiada w swojej strukturze liczne pętle tzw. sprzężeń zwrotnych ujemnych, służących zachowaniu integralności systemu (Namysłowska, 2000)ํㅗㄹ Rodzina, jak każdy system, charakteryzuje się ekwipotencjalnością (nie jest możliwa do przewidzenia droga rozwoju różnych systemów rodzinnych o analogicznej sytuacji wyjściowej) oraz ekwifinalnością (co oznacza, że różne drogi mogą prowadzić do porównywalnie podobnego stanu końcowego różnych systemów rodzinnych) (de Barbaro, 1999b).

Każda rodzina posiada swoje własne „ego rodzinne”, które jest niezależne od „ego” poszczególnych jej członków. Stopnie skonsolidowania "ego rodzinnego" z "ego" poszczególnych jej członków jest różne w różnych rodzinach. Rodziny ze zbyt skonsolidowanym "ego" mogą być rodzinami dysfunkcyjnymi z licznymi objawami psychosomatycznymi (Goldenberg, Goldenberg, 2006).

Każda rodzina posiada także wewnętrzne mity transgeneracyjne, dziedziczone z pokolenia na pokolenie, które stanowią o wspólnej tożsamości i są ważną podstawą rozwoju osobowości jej członków. Mity transgeneracyjne są więc czynnikiem kształtującym tożsamość człowieka, jego egzystencjalną niezależność i poczucie podmiotowości (Namysłowska, 2000)². W ujęciu systemowym rodzina ma precyzyjnie wyodrębnione granice, gdyż do rodziny nuklearnej albo się należy albo nie i nie ma form pośrednich (tamże).

Choroba pełni w rodzinie funkcję regulacyjną. Zapada na nią najczęściej „najsłabsze ogniwo" rodziny, a jego trudności zdrowotne mają za zadanie przywrócić integralność systemu. Jest to tak zwana morfostatyczna funkcja choroby (de Barbaro, 1999a). Inaczej

${ }^{1}$ Przykładem może być ojciec zdradzający matkę, na co córka reaguje anoreksją i przez to wymusza powrót ojca na łono rodziny. $\mathrm{W}$ ten sposób zachowana zostaje integralność struktury rodziny (de Barbaro, 1999b).

2 Przykładem takiego mitu mogą być następujące stwierdzenia: $w$ naszej rodzinie wszyscy mają studia, $w$ naszej rodzinie wszyscy sa katolikami, pochodzimy $z$ arystokracji $i$ gardzimy ludźmi $z$ plebsu. Każdego członka rodziny obowiązuje lojalność wewnątrzrodzinna (ang. legacy), która jest bardzo mocno przestrzegana (np. w transgeneracyjnym micie - "wtasne brudy pierze się w domu") (Namysłowska, 2000). 
mówiąc, rodzina tak jakby "oddelegowuje" swojego najsłabszego członka do "bycia chorym”, w celu opiekowania się nim, koncentrowania uwagi wokół jego problemów i w ten sposób zachowania integralności systemu.

Systemowa terapia rodzin powstała właśnie $\mathrm{z}$ myślą o chorych na schizofrenię. Uważano, że przyczyną schizofrenii jest reakcja najsłabszego członka rodziny na obecność tzw. matki schizofrenogennej, które to pojęcie sformułowała Frieda Fromm-Reichman (za: Hartwell, 1996). Zgodnie z tą koncepcją matka schizofrenogenna miałaby być matką chłodną i podświadomie odrzucającą dziecko. Mechanizmy obronne u dziecka oraz funkcje morfostatyczne w rodzinie "delegują" najsłabszego członka do wybuchu psychozy jako reakcji na komunikaty o charakterze tzw. podwójnego wiązania ${ }^{3}$ wydawane przez matkę schizofrenogenną. Omamy i urojenia miały pełnić funkcję równoważącą chłód emocjonalny i dystans, jaki prezentuje matka schizofrenogenna. Inaczej rzecz ujmując, systemowi terapeuci rodzinni upatrywali tła schizofrenii $w$ nieprawidłowych relacjach wewnątrzrodzinnych o charakterze przewlekłej traumy posiadania chłodnej, racjonalnej matki wydającej dziecku komunikaty o charakterze podwójnego wiązania (tamże).

\section{Krytyka genezy schizofrenii w kontekście systemowego rozumienia rodziny}

Już od lat 80. XX wieku wiadomo, że nie da się obronić tezy, jakoby przyczyną schizofrenii była struktura rodziny nuklearnej (za: Harrington, 2012). Badania empiryczne wykazały, że tzw. matka schizofrenogenna może występować równie często u osób chorych na schizofrenię, jak i zdrowych.

Rodzina traktowana jest jako wsparcie chorego, a nie jako przyczyna patologii (Seeman, 2009). Od dawna bowiem wiadomo, że pacjenci chorzy na schizofrenię, którzy założyli własne rodziny lub są członkami rodzin funkcjonują w przebiegu choroby znacznie lepiej niż osoby samotne. Rodzina jest zatem czynnikiem ochronnym przed ciężkim przebiegiem psychozy. Ponadto zauważono, że koncepcja matki schizofrenogennej stygmatyzowała rodziny osób chorych na schizofrenię, wywołując $u$ nich silne poczucie winy z powodu upatrywania źródeł choroby w rodzinnym kręgu. Analogiczna sytuacja występuje w przypadku autyzmu, który psychoanalitycy tłumaczyli podświadomym

\footnotetext{
${ }^{3}$ Podwójne wiązanie - to termin wprowadzony przez Gregory'ego Batesona opisujący sytuację otrzymywania sprzecznych komunikatów od ważnej osoby. Na przykład matka daje synowi koszulę białą i czarną. Gdy ten zakłada czarną, jest niezadowolona, że nie założył białej, a gdy zakłada białą, jest niezadowolona, że nie założył czarnej.

Często podwójne wiązanie pojawia się w odniesieniu do zbliżania/separacji dziecka - matka nie potrafi znieść zarówno indywiduacji dziecka, jak i jego symbiotycznych skłonności.

Bateson zakładał, że podwójne wiązanie jest częstym rodzajem komunikacji przez rodziny, w których obecna jest schizofrenia, a w umyśle dziecka odzwierciedla się chaos i sprzeczność w komunikacji między członkami rodziny (Bateson, Jackson, Haley \& Weakland, 1956). Badania nie potwierdziły tej hipotezy.
} 
odrzuceniem dziecka przez rodziców (za: Feinstein, 2010). Obie te koncepcje o charakterze stygmatyzującym uważa się za przestarzałe i nieaktualne.

\section{Zalety systemowej terapii rodzin}

Korzystny wpływ terapii systemowej rodziny na osoby chore na schizofrenię wynika przynajmniej z kilku aspektów:

1. Pytania cyrkularne zadawane $\mathrm{w}$ terapii rodzin dają możliwość bliższego przyjrzenia się członkom rodziny i problemom pacjenta (Chrząstowski, 2014). Zapewniają szansę zrozumienia przeżyć psychotycznych i rozumienia deficytów, z którymi chory musi sobie radzić w codziennym życiu. Omawianie ich na łonie rodziny otwiera zrozumienie problemów pacjenta przez pozostałych członków i odmitologizowuje schizofrenię, która w powszechnym przekonaniu jest chorobą przerażającą i zagrażającą otoczeniu.

2. Metodą badań empirycznych wykazano, że zmniejszenie wskaźnika ujawniania emocji przez rodzinę zmniejsza liczbę nawrotów schizofrenii ${ }^{4}$. Szczególnie obniżenie negatywnych emocji $\mathrm{w}$ rodzinie, czasem transformowanych $\mathrm{w}$ np. nadmierną opiekuńczość wobec chorego, wydaje się priorytetowym zadaniem. Psychoedukacja jako propozycja terapeutyczna opiera się na założeniu, że rodzina może stać się ważnym partnerem $\mathrm{w}$ procesie rehabilitacji oraz prewencji nawrotów, będąc wsparciem dla pacjenta. Wyniki badań dotyczących pracy nad zmniejszeniem wskaźnika ujawniania emocji - nie tylko negatywnych, ale i pozytywnych są empiryczną weryfikacją skuteczności systemowej terapii rodzin $\mathrm{u}$ chorych na schizofrenię (por. np. Kordas, Kokodyńska, Kurtyka, Sikorska, Walczewski, Bogacz, 2015). Dostarczenie wiedzy oraz umiejętności, aby zachować zdolność do myślenia w sytuacji kryzysowej, ma zapobiec nadmiernej dominacji przeżyć.

3. Psychoedukacja rodziny, wprowadzana jako element terapii systemowej rodziny, wyposaża jej członków w warsztat fachowej wiedzy o chorobie, dając w ten sposób narzędzie do pracy z zaostrzeniami choroby i z kryzysem (Dixon, Adams, Lucksted, 2000; Goldstein, Miklowitz, 1995; Kordas, Kokodyńska, Kurtyka, Sikorska, Walczewski, Bogacz, 2015)5. Już we wczesnych latach 80. XX wieku grupa

\footnotetext{
${ }^{4} \mathrm{~W}$ latach 70. ubiegłego wieku badacze opisujący rolę środowiska rodzinnego zauważyli, że natężenie ujawnianych przez bliskich krewnych chorego uczuć (wskaźnik UU) ma znaczący wpływ na długość remisji. Chorzy, których rodziny charakteryzowały się niższym wskaźnikiem ujawnianych uczuć, zarówno tych negatywnych (wrogość, krytycyzm, emocjonalne naduwikłanie), jak i tych pozytywnych (ciepło, pozytywne uwagi), mieli mniej nawrotów. Badania kliniczne potwierdzają, że chorzy żyjący $\mathrm{w}$ rodzinach o wysokim wskaźniku UU mają ponad dwukrotnie podwyższone współczynniki nawrotowości schizofrenii (Amaresha, Venkatasubramanian, 2012).

${ }^{5}$ Jak donoszą wyniki badań, psychoedukacja rodziny redukuje jej obciążenie emocjonalne. Spadek tego obciążenia u bliskich może przyczyniać się do obniżenia poziomu ujawnianych uczuć w rodzinie, co z kolei może zmniejszać zarówno ilość nawrotów chorobowych, jak i ich intensywność.
} 
pracowników socjalnych sformułowała nowy paradygmat terapii rodzin - nurt psychoedukacyjny (Harrington, 2012). „Pogrzebał” on koncepcję matki schizofrenogennej, traktując ją jako teorię niepodpartą dowodami naukowymi i zbyt mocno uwikłaną w ortodoksyjne myślenie psychoanalityczne (Johnston, 2013).

4. Systemowa terapia rodziny umożliwia przepracowanie własnych problemów przez zdrowych członków rodziny, co bardzo poprawia wewnętrzne relacje interpersonalne i przyczynia się do lepszego funkcjonowania całości, w tym także samego chorego (Neill, 1990).

\section{Podsumowanie}

Mimo opisanego wyżej współczesnego rozumienia schizofrenii zaprzeczającego przyczynom powstawania schizofrenii upatrywanym $\mathrm{w}$ zachowaniach tzw. schizofrenogennej matki, koncepcja ta czasami nadal bywa obecna w obszarze medycyny i prawa, co może niejednokrotnie prowadzić do stygmatyzującego poszukiwania przyczyn schizofrenii $\mathrm{w}$ nieprawidłowych oddziaływaniach rodzicielskich we wczesnych okresach rozwoju człowieka.

Stąd też podsumowując warto podkreślić potrzebę upowszechniania współczesnej wiedzy dotyczącej przyczyn schizofrenii, jak i znaczenie stosowania terapii systemowej, jak i psychoedukacji wobec pacjenta i jego rodziny, która dotyczy wyposażenia jej w kompetencje poznawcze i umiejętności działania związane z chorobą.

Badania nad efektywnością oddziaływań terapii systemowej połączonej z psychoedukacją pacjentów ze schizofrenią i ich rodzin wskazują na znaczące zmniejszenie ilości nawrotów choroby i hospitalizacji, na lepsze funkcjonowanie społeczne, zwiększenie wiedzy i wglądu w chorobę oraz poprawę samooceny chorych, ale także mają istotny wpływ na zmniejszenie obciążenia rodzin pacjentów, na wzrost ich poczucia sprawstwa

Terapia systemowa wraz z psychoedukacją rodzin jest niezwykle ważna. Jednym z najważniejszych jej efektów jest obniżenie obciążenia emocjonalnego rodziny chorobą, a poprzez to spadek poziomu ekspresji, szczególnie trudnych emocji w rodzinie, co przekłada się na spadek ryzyka nawrotu choroby. W wyniku tego typu działań następuje nie tylko wzrost wiedzy rodziny o chorobie bliskiego, ale także nabywanie umiejętności

Postępowanie psychoedukacyjne wobec rodziny powinno być dostosowane do etapu choroby. $\mathrm{W}$ fazie ostrej polecane jest głównie odbarczenie emocjonalne i dostarczanie wiedzy o chorobie. W fazie powracania do zdrowia rodzina powinna otrzymywać wskazówki co do minimalizowania ewentualnych nawrotów choroby $\mathrm{u}$ osoby bliskiej. Istotnymi zaleceniami dla efektywnej psychoedukacji członków rodziny pacjenta chorującego na schizofrenię jest zasada partnerstwa, regularności spotkań, skupienia się na najważniejszych problemach pacjenta oraz repetycji wiadomości i utrwalanie ich poprzez zadania domowe. Znaczenie stosowania psychoedukacji wobec rodziny pacjenta chorującego na schizofrenię dotyczy wyposażenia jej w cenne kompetencje poznawcze i umiejętności działania związane z chorobą (za: Kordas, Kokodyńska, Kurtyka, Sikorska, Walczewski, Bogacz, 2015). 
wspierania chorego oraz redukowanie stresu w rodzinie, a także rozwijanie umiejętności budowania wsparcia potrzebnego choremu i całej jego rodzinie.

\section{Bibliografia:}

Addington, J.M.A. (2005). Three-year outcome of family work in an early psychosis program, Schizophrenia Research, 79, 107-116.

Andreasen, N.C. (2010). The lifetime trajectory of schizophrenia and the concept of neurodevelopment, Dialogues in Clinical Neuroscience, 3 (12), 409-415.

Amaresha, A.C., Venkatasubramanian, G. (2012). Expressed emotion in schizophrenia: an overview, Indian Journal of Psychological Medicine, 1 (34), 12-20.

Bateson, G., Jackson, D.D., Haley J. \& Weakland, J. (1956). Toward a Theory of Schizophrenia, Behavioral Science, vol. 1, 251-264.

Chrząstowski, S. (2014). Nie tylko schemat: praktyka systemowej terapii rodzin, Warszawa: Wydawnictwo Paradygmat.

De Barbaro, B. (1999a). Schizofrenia w rodzinie, Kraków: Wydawnictwo Uniwersytetu Jagiellońskiego.

De Barbaro, B. (1999b). Wprowadzenie do systemowego rozumienia rodziny, Kraków: Wydawnictwo Uniwersytetu Jagiellońskiego.

Dixon, L., Adams, C., Lucksted, A. (2000). Update on Family Psychoeducation for Schizophrenia, Schizophrenia Bulletin, 1 (26), 5-20.

Feinstein, A. (2010). A History of Autism. Conversations with the Pioneers, Chichester: WileyBlackwell.

Foley, P.B. (2019). Dopamine in psychiatry: a historical perspective, Journal of Neural Transmission, 126, 473-479.

Genderson, M.R., Dickinson, D., Diaz-Asper, C. M., Egan, M. F., Weinberger, D.R., Goldberg, T. E. (2007). Factor analysis of neurocognitive tests in a large sample of schizophrenic probands, their siblings, and healthy controls, Schizophrenia Research, 1-3 (94), 231239.

Goldenberg, H., Goldenberg, I. (2006). Terapia rodzin, Kraków: Wydawnictwo Uniwersytetu Jagiellońskiego.

Goldstein, M.J., Miklowitz, D.J. (1995). The effectiveness of pychoeducational family therapy in the treatment of schizophrenic disorder, Journal of Marital and Family Therapy, 4 (21), 361-376.

Harrington, A. (2012). The fall of the schizophrenogenic mother, The Lancet, 379 (9823), $1292-$ 1293.

Hartwell, C.E. (1996). The Schizophrenogenic Mother Concept in American Psychiatry, Psychiatry, 3 (59), 274-297. 
Johnston, J. (2013). The ghost of the schizophrenogenic mother, Virtual Mentor, 9 (15), 801805.

Kordas, W., Kokodyńska, K., Kurtyka, A., Sikorska, I., Walczewski, K., Bogacz, J. (2015). Rodzina wobec schizofrenii - grupa psychoedukacyjna w programie pilotażowym, Psychiatria Polska, 6 (49), 1129-1138, doi: http://dx.doi.org/10.12740/PP/38934.

Lipska, B.K. (2004). Using animal models to test a neurodevelopmental hypothesis of schizophrenia, Journal of Psychiatry \& Neuroscience, 4 (29), 282-286.

Morris, J.A. (2012). The fall of the schizophrenogenic mother, The Lancet, 14, 380(9837), 110.

Murray, R.M., Lewis, S.W. (1987). Is schizophrenia a neurodevelopmental disorder?, British Medical Journal (Clinical Research Ed.), 295 (6600), 681-682.

Namysłowska, I. (2000). Terapia rodzin, Warszawa: Wydawnictwo Instytutu Psychiatrii i Neurologii.

Neill, J. (1990). Whatever became of the schizophrenogenic mother?, American Journal of Psychotherapy, 4 (44), 499-505.

Pietras, T., Witusik, A., Panek, M., Rodak, J., Szemraj, J. (2012). Neurorozwojowy paradygmat patogenezy niepełnosprawności intelektualnej, (w:) K. Bobińska, T. Pietras, P. Gałecki (red.), Niepetnosprawność intelektualna-etiopatogeneza, epidemiologia, diagnoza, terapia, 93-110, Wrocław: Wydawnictwo Continuo.

Seeman, M.V. (2009). The Changing Role of Mother of the Mentally Ill: From Schizophrenogenic Mother to Multigenerational Caregiver, Psychiatry, 72 (3), 284-294.

Stahl, S.M. (2013). Stahl's Essential Psychopharmacology. Neuroscientific Basis and Practical Applications, New York: Cambridge University Press.

Thornicroft, G., Tansella, M. (2010). W strone lepszej psychiatrycznej opieki zdrowotnej, Warszawa: Wydawnictwo Instytutu Psychiatrii i Neurologii.

Weinberger, D.R. (1987). Implications of normal brain development for the pathogenesis of schizophrenia, Archives of General Psychiatry, 44 (7), 660-669. 